\title{
Cashing in on innovation: a taxonomy of FinTech
}

\author{
Michael B. Imerman ${ }^{1} \cdot$ Frank J. Fabozzi ${ }^{2}$
}

Published online: 9 May 2020

(c) Springer Nature Limited 2020

\begin{abstract}
In this article, we provide a taxonomy of the different types of innovation occurring in financial services, a framework which we refer to as our FinTech Ecosystem. We use this FinTech Ecosystem to highlight the various areas of potential value for investors who are looking into ventures in this space as alternative investments. Our conceptual framework enables investors to examine emerging technologies and FinTech verticals through the lens of a sector analysis. To better understand where the FinTech Revolution started and where it is going, we apply the concept of digital transformation to the financial services industry which allows us to highlight the delicate risk-reward balance in FinTech.
\end{abstract}

Keywords FinTech · Digital transformation · FinTech Ecosystem · Financial innovation · Technological innovation . FinTech Revolution

\section{Introduction}

Today, FinTech is one of the hottest areas in finance. According to data from Venture Scanner, from 2010 through the end of 2019 - a period we refer to as the "FinTech Revolution"more than $\$ 165.5$ billion poured into FinTech companies. FinTech is still an area that is not well understood and, certainly, this is an area that may be overlooked by investors who are looking to diversify into non-standard industry sectors. In this article, we build a conceptual framework that we believe can be used by investors who are looking for value in the growth of the FinTech sector. We begin by defining FinTech and then proceed to establish a taxonomy of the different areas within FinTech which we refer to as our "FinTech Ecosystem." This conceptual framework can be used by investors seeking to diversify their allocation to alternative investments by identifying FinTech companies with the most promising areas and/or technologies (what we refer to as FinTech verticals and horizontals, respectively). Thus, investors can develop a strategy akin to allocating across

Michael B. Imerman

michael.imerman@cgu.edu

Frank J. Fabozzi

frank.fabozzi@edhec.edu

1 Drucker School of Management, Claremont Graduate University, Claremont, CA, USA

2 EDHEC School of Business, Nice, France sectors along the different FinTech verticals or obtaining more broad-based coverage by investing in the emerging technologies themselves (i.e., FinTech horizontals).

To better understand where the FinTech Revolution started and where it is going, we apply the concept of digital transformation to the financial services industry. Digital transformation, as we apply it, relies on a catalyst. The catalyst that really thrust FinTech innovations into the limelight was the Global Financial Crisis (GFC). The catalyst that will ensure that the most promising FinTech innovations are more widely adopted and that the ones that do not provide a solution to consumers and businesses will fall by the wayside is the COVID-19 pandemic. Therefore, the idea of digital transformation allows us to highlight the delicate risk-reward balance in FinTech. While it may be the case that funding was plentiful and valuations were frothy over the past few years, the market correction that started in the first quarter of 2020 has put into motion the kind of economic Darwinism that we saw when the Dot-Com bubble burst in 2001-2002. Very few would argue that society has benefitted from the exponential growth in e-commerce and technology since the early 2000s, but the bursting of the bubble ensured that smart capital went to the most promising ideas, and that is what is likely to happen in FinTech over the next couple of years.

In general, FinTech refers to the application of new technology in providing financial solutions to individuals and firms. More specifically, the trend that has arisen 
since the GFC - a trend referred to later as the "FinTech Revolution"-is that technology firms have moved in and begun to offer services that have been only offered by traditional financial institutions. Pure technology companies that historically have had nothing to do with financesoftware development firms, hardware manufacturers, e-commerce companies, mobile technology, and data analytics platforms-are seeking to take business away from banks, asset management firms, brokerage firms, insurance companies, and other household names that have provided these financial services for decades (even centuries for some). Adding to the intrigue of FinTech is that many of the financial regulations that provide the rules by which those traditional financial institutional institutions must play in the USA, were written in the last century in large part in response to the Great Depression.

Our FinTech Ecosystem, described in the next section, can be viewed as a roadmap for understanding the landscape of FinTech innovation. One distinguishing feature of our ecosystem (setting us apart from other such ecosystems) is that we categorize by "vertical sectors"-innovations in digital banking, innovations in payments, innovations in lending, innovations in wealth management, innovations in insurance, and the like-and "horizontal" functional areas and emerging technologies. The FinTech verticals can be viewed by external investors (i.e., nonfounders and non-employees) within the lens of sector allocations. The functional areas can be viewed by FinTech start-ups and financial services firms as areas in which they need to invest internally. And the emerging technologies can be viewed by both parties-internal and external investors-as potential opportunities for future growth.

\section{The FinTech Ecosystem}

FinTech is a very broad field and the landscape is changing rapidly. There are several examples in recent research that have sought to provide structure for the FinTech space. We draw from these resources as we attempt to paint a picture of the FinTech landscape. However, we create our own taxonomy of FinTech Ecosystem. First we consider the different areas within financial services (which we refer to as "FinTech verticals") and then the different functional areas (i.e., regulation, risk management, funding, etc.), as well as the technologies that are likely to drive innovations in financial services (which collectively we refer to as "FinTech horizontals"). This is what we will refer to as our "FinTech Ecosystem." Figure 1 is a visualization of our FinTech Ecosystem, which we discuss in this section.

\section{FinTech verticals}

We first describe the different areas within financial services that are being impacted by new technologies which we refer to as "FinTech verticals" in our FinTech Ecosystem. The first is payments technology. As an example, FinTech firms are developing new technology to make payments with a smartphone or other mobile electronic device. We also group money transfer services here since the line gets a little blurry in the case of transfer services and payments technologies. For example, how does one classify a service such as WeChat Pay? This mobile payment app, which was developed by Chinese tech giant Tencent and is accessible through the WeChat social networking and messaging app, is essentially just transferring funds from your bank account to your associate's bank account. The same can be said for Venmo and Zelle, given that Venmo was acquired by PayPal and Zelle was the incumbent banks' response. The Big Five tech companies in the USA have also planted their stakes in the payments space. Except for Microsoft, all these firms have had a payments app at one time or another.

\section{Payments technology}

According to Venture Scanner, since 2010 (through the first quarter of 2020) there has been $\$ 90.4$ billion invested into the payments sector. Overall, there have been 763 successful exits (551 acquisitions and 212 IPOs). Acquisitions include Bill Me Later being acquired by eBay in 2008, Clover's being acquired by First Data in 2012, and PayPal's acquisition of iZettle in 2018 for $\$ 2.2$ billion. Perhaps the highest profile IPO was Square in 2015 which was priced at $\$ 9$ per share with a total valuation of $\$ 2.9$ billion (as of April 17, 2020 Square closed over $\$ 60$ per share). Of all the FinTech verticals, this seems to be the one that is most mature. That is not to say that new innovations will not be arising in this space (they will, especially with emerging technologies such as biometrics and blockchain discussed below) but less likely to have the large payoffs that were seen several years ago.

\section{Digital banking}

Another important area in the FinTech Ecosystem is digital banking. Within this space, we have online and mobile banking operations that almost all traditional commercial and retail banks operated for years. This is an example of how traditional banks are a juxtaposition in the world of financial services. Although they hold onto their legacy businesses (branches, call centers, check processing facilities, and mainframe computers), management of these firms know 


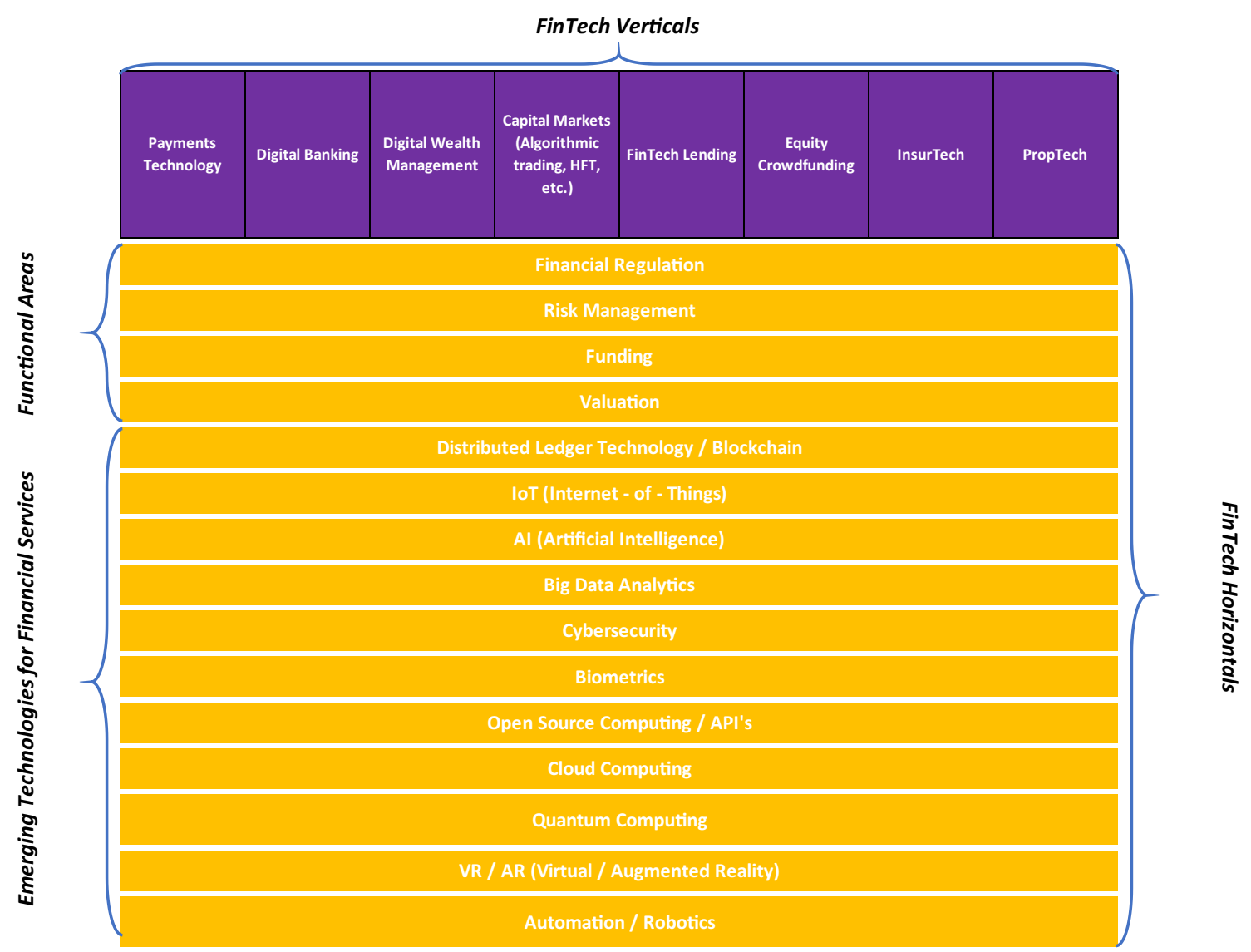

Fig. 1 FinTech Ecosystem. Source: Prepared by the authors

what they need to do to keep up with the digital revolution in banking and invest in their online banking platforms and mobile technology as well as more cutting-edge technologies such as cloud computing and artificial intelligence-driven solutions.

Although we also have observed recently an influx of tech-driven start-ups into banking, these "neo-banks" or "challenger banks," as they are becoming more widely known, have little or no physical presence but rather provide all services through their apps and websites. ${ }^{1}$ Their exclusive reliance on technology makes them strong competitors in the digital banking space, but it could also pose new risks. Examples of these types of FinTech companies in this space

\footnotetext{
1 Although sometimes used interchangeably, there are subtle differences between the two. We make the distinction as follows. First, neobanks do not have a banking license; often they partner with incumbent institutions to provide support. Neo-banks also usually have a limited product line ("core banking products") and augment their produce line with personal financial management tools. In contrast, challenger banks may have recently received a banking or other financial license but are relatively new to the industry. Challenger banks tend to offer a fuller suite of products.
}

include Monzo, Revolut, and Starling Bank in the UK, as well as Chime, Simple, and Varo Money in the USA. The rise of these challenger banks and neo-banks over the last decade is no coincidence. As we will discuss in the section describing the FinTech Revolution, the lack of trust and confidence in the big banks after the GFC sowed the seeds for today's FinTech innovations. However, in the latest crisis during the COVID-19 pandemic, bank customers are falling back on the brands that they have come to trust over the course of their lives and seem less inclined to use a start-up company for their primary banking needs.

This is a dramatic shift from the trend that we have seen over the last two years and complicates the dynamics in the digital banking vertical a bit. In response to stay-at-home orders, the largest global banks are discouraging customers from visiting branches and rather are encouraging that their Web-based and mobile solutions be used during this time. This is all within the realm of digital transformation, the concept we utilize below, and could play out in one of three ways. First, it could provide headwinds to the growth of neobanks and challenger banks ultimately leading to a shortage of funds and their demise. Second, it could accelerate partnerships between FinTech start-ups in banking and the 
traditional or incumbent banks (even outright acquisitions of neo-banks/challenger banks by the big global banks and larger regional banks). Third, it could play to the favor of FinTech start-ups in banking as customers of the big banks become frustrated with subpar service, technical glitches, and user experience at the incumbent, thereby driving more money back into the neo-banks and challenger banks.

\section{FinTech lending}

Another popular area in the FinTech Ecosystem is lending. Traditional consumer and commercial lending are being transformed by this innovation, such as obtaining a mortgage loan online. Many FinTech lenders use proprietary technology, machine learning algorithms, and Big Data analytics to identify potential borrowers, evaluate their risk, and then set the terms of the loan including the loan rate. The amazing thing is that this can often be done in the amount of time it takes to make a pot of coffee!

We can break this part of the Ecosystem into three different categories: (1) online exchanges (such as Lending Tree), (2) online lenders (such as Rocket Mortgage which is owned by Quicken Loans), and (3) peer-to-peer (or P2P) lenders (such as Lending Club). The third category represents a new mechanism for borrowing and lending. Initially, P2P lenders provided a platform to allow individual borrowers to enter their funding needs and then, instead of going to a bank or other lender for a loan, the funds are borrowed directly from other individuals or groups of individuals that are looking for alternative places to invest, rather than buying stocks or bonds or putting their funds into a savings accounts. Hence, P2P lenders matched borrowers who require funds with "peer" lenders, or individual investors. This is an example of disintermediation, ${ }^{2}$ which is an underlying theme in the economics of FinTech that should be considered when evaluating business plans of innovative startups.

There has been a trend in recent years towards what has been referred to as reintermediation. The business model of these P2P lenders has shifted since their early days. A very small portion of their funds are coming from individual investors in the form of micro-loans, but rather the loans tend to be funded by warehouse credit facilities from large financial institutions and then sold off either as wholeloans or bundled together into asset-backed securities. As a result, P2P lenders are more commonly known now as Marketplace Lenders (or MPLs). This reversed the practice of

\footnotetext{
${ }^{2}$ Disintermediation in general means removing in a supply chain a third-party that receives compensation for providing a service that results in the completion of a transaction. In finance, where it is referred to as financial intermediation, the term means cutting out the fee paid to a bank, broker, dealer, or other intermediary used to complete a financial activity.
}

disintermediation, a term referred to as reintermediation. An innovative firm falling somewhere in between our categorization of an online lender and a MPL is CommonBond. ${ }^{3}$ That firm helps college graduates refinance student loans at competitive rates using technology, Big Data, algorithmic risk models, and the securitization market.

According to Venture Scanner, since 2010 (through the first quarter of 2020) there has been $\$ 75.96$ billion invested into FinTech companies specializing in lending (both consumer and business lending). Overall, there have been 463 successful exits (263 acquisitions and 200 IPOs). Two successful IPOs in this space include one of the original P2P lenders, LendingClub, that went public in 2014 with $\$ 865.5$ million raised and more recently GreenSky which went public in 2018 raising $\$ 874$ million. In terms of acquisitions, the FinTech lender Earnest was acquired by the student loan specialty finance company Navient in 2017 for $\$ 155$ million and in 2018 Atlanta-based Kabbage, which provides credit solutions for small and mid-sized business, acquired Orchard.

Once the global economy recovers, FinTech lenders who are able to weather the proverbial storm will likely be in a good position for raising additional capital and successful exiting. There is a lot of promising innovation going on in this space, so while it is neither the newest nor the hottest vertical, it has a lot of potential for further success.

\section{Digital wealth management}

The wealth management industry has seen considerable technological innovation and disruption in recent years. These innovations include the rise of so-called robo-advisors who use sophisticated software to generate investment advice and portfolio allocations for their clients with little or no human intervention. Examples of innovators in the digital wealth management space include the market leaders in robo-advisory Betterment and WealthFront, a SigFig (a robo-advisor), Acorns (a micro-investing and robo-advisor platform), and Vanguard (an "incumbent" in the wealth management industry).

The retail investing subsector of this FinTech vertical has raised $\$ 5.22$ billion between 2010 and the first quarter of 2020. Yearly amounts spiked in 2018 with over \$1.4 billion being raised in that year alone, almost twice what was raised the previous year. The next year is likely to be critical for digital wealth management for at least three reasons. First, retail solutions in the digital wealth management vertical-including the companies we named above-are growing in popularity and not just with the digitally native demographics (millennials and Gen-Z) but also with older

\footnotetext{
${ }^{3}$ In fact, CommonBond's founder refers to their firm as a "FinTech Lender.'
} 
wealthier clients who have come to accept these products. Second, stay-at-home measures make using a digital wealth management solution more attractive during the COVID-19 pandemic as clients are limited in having in-person meetings with their financial advisors and are more likely to use online/digital solutions. Both of those could provide some support for digital asset management businesses. Yet, lastly, one counterpoint to these positive factors is that roboadvisory start-ups such as Wealthfront, Betterment, SigFig, and Acorns have never been through a bear market. Typically, they invest in broad-based ETFs, so their performance should not lag the market as a whole too much, but it will still be a challenge for them to prove to their clients and investors that they can weather a downturn.

There has already been a decent track record of exit activity in the retail digital wealth management space. According to Venture Scanner, there were 11 IPOs and 103 acquisitions over the life of their dataset. E-Trade has actually been a very active acquirer of start-ups in this area including $\$ 750$ million they spent on OptionsHouse in 2016. ${ }^{4}$ BlackRock acquired the robo-advisory start-up FutureAdvisor for $\$ 150$ million in 2015 in the first major deal between an incumbent and a FinTech start-up in the asset management industry. Canadian robo-advisor WealthSimple joined forces with Purpose Advisor Solutions in January 2020. In terms of IPO's, there were only two notable deals since 2010, neither of which are US-based: SelfWealth (an Australian FinTech that raised \$7.34 million in their 2017 IPO) and Tiger Brokers (a Chinese FinTech that raised \$104 million in their 2019 IPO).

\section{Capital markets}

On the institutional side, traders who would make buy and sell decisions on the trading desks are now competing with algorithms that are programmed to execute transactions in a fraction of the time. The institutional investment subsector within this FinTech vertical has raised over $\$ 4$ billion between 2010 and the first quarter of 2020. Yearly funding peaked in 2018 with over $\$ 1$ billion being raised in that year alone. Funding amounts fell 35\% in 2019 with only $\$ 674$ million being raised in that year, suggesting that investment in those companies may be slowing. Rather, behind the scenes data analytics firms that provide support to capital markets has some of the strongest growth potential and overlaps with some of the most exciting FinTech horizontals that we discuss below.

\footnotetext{
${ }^{4}$ In February 2020 it was announced that Morgan Stanley would acquire E-Trade for $\$ 13$ billion in a continued trend of consolidation between full service brokerage houses and discount brokers.
}

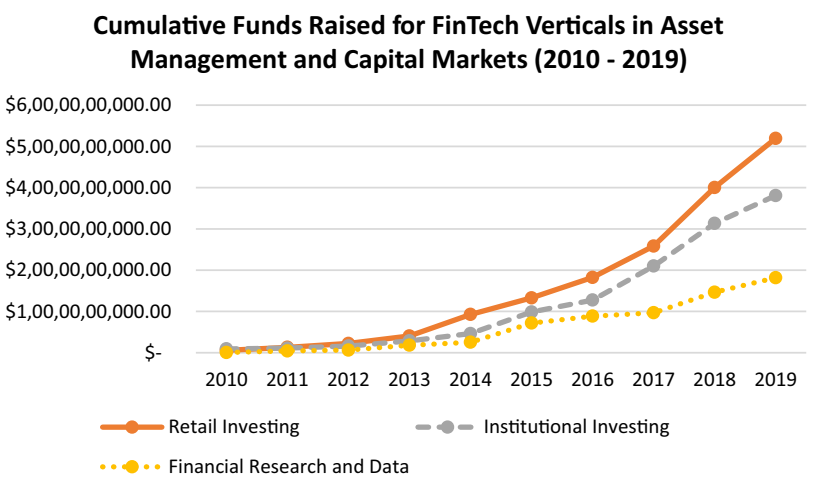

Fig. 2 Cumulative funding for FinTech verticals in asset management and capital markets from 2010 through 2019. Source: Prepared by the authors with Venture Scanner data

In the Venture Scanner database, under the subsector "Financial Research and Data" funding went from just over $\$ 82$ million in 2017 to $\$ 497$ million in 2018 . This space includes companies such as Kensho which was founded in 2013 in Cambridge, Massachusetts, which uses natural language processing (NLP) algorithms and Big Data Analytics to unlock hidden value for institutional investors. They have raised a total of $\$ 67.5$ million to date including \$10 million in seed funding in 2014 from a consortium of venture capital firms which was followed by a major $\$ 7$ million investment from Goldman Sachs later than year. In 2017 they raised $\$ 50$ million in Series B funding from some of the biggest names on Wall Street including Bank of America Merrill Lynch, Citigroup, JP Morgan Chase, Morgan Stanley, Wells Fargo, Standard \& Poor's, and more. PeerIQ, another interesting company in this space, specializes in risk analytics and pricing in the peer-to-peer lending market including asset-backed securities that are issued by P2P lending companies. PeerIQ raised \$20.5 million in early stage (Series A) financing from a consortium of venture capital firms as well as TransUnion.

Figure 2 shows the cumulative funding amounts for three FinTech subsectors relevant to our most recently discussed FinTech verticals (Digital Wealth Management and Capital Markets): retail investing, institutional investing, and financial data and research. Although all of these subsectors began the decade with annual funding amounts in the millions, they all accelerated reaching the $\$ 1$ billion mark. Retail investing (solid curve) FinTech companies had the earliest start breaching $\$ 1$ billion in funding by 2015 . Institutional investing (dashed curve) FinTech companies breached $\$ 1$ billion in funding the following year. Financial research and data analytics (dotted curve) companies' funding almost reached \$1 billion 2017 (\$969 million) but then almost doubled by 2019 . We think that given the investment in some of the emerging technologies discussed in the next section, this area will continue to see exciting growth. 


\section{Equity crowdfunding}

Equity crowdfunding is essentially the equity-based counterpart to P2P lending as discussed above. In fact, we like to think of the distinction between P2P lending and equity crowdfunding as analogous to the distinction between debt and equity in capital markets. Whereas P2P lending marketplaces allow individuals to raise money by borrowing from others looking to invest their funds, equity crowdfunding platforms allow individuals and organizations to raise money by giving the investor a stake in the project's success. The upside return on investing through these platforms varies from an actual ownership stake with profit sharing to sometimes "paid in kind" type of rewards where investors receive products or other prizes for providing funds. In some cases, the crowdfunding platform specializes in raising money for charitable causes.

Crowdfunding ventures, ironically, have raised the least amount of funds of all the FinTech verticals. From 2010 through the first quarter of 2020 less than $\$ 915.5$ million was raised according to Venture Scanner. The yearly average amount of funding over the period from 2016 to 2019 is just over $\$ 112$ million. There have been no IPO's in this space and only 65 acquisitions recorded in the entire Venture Scanner database for crowdfunding firms. Airbnb acquired crowdfunding site Tilt.com in 2017, and SeedInvest, an equity crowdfunding platform founded in 2011, was bought by Circle in 2018. Circle is a FinTech company specializing in blockchain technology and cryptoassets. In fact, the world of cryptoassets, often incorrectly viewed as one-in-the-same with FinTech although our ecosystem shows that is not the case, can also be viewed as a way in which FinTech is transforming capital markets.

\section{InsurTech}

In our FinTech Ecosystem, InsurTech refers to the application of technological innovation to the insurance industry. All categories of insurance companies are relying on technology and advanced data analytics more than ever. Insurance, like other sectors of the financial services industry, has experienced many technology and data-driven innovations since the GFC. Many of these innovations leverage connected devices. In Fig. 1, this is labeled "emerging technologies" and falls under the Internet-of-Things or IoT. The idea is that from data obtained from wearable sensors (e.g., a FitBit or Apple Watch) or from the dashboard of an automobile (Progressive and State Farm offer these dongles that attach under the car's dashboard, referred to as an onboard diagnostic port), insurance companies have much more access to real-time and near-continuous data about our health, driving habits, and other behaviors. This, in turn, can allow insurance companies to dynamically reprice insurance policies: safer and healthier behavior (working out regularly or driving under the speed limit) can lead to reduced life insurance or car insurance premiums, respectively. Insurance companies do not make the use of these trackers mandatory but rather give the consumer the option to use them. We see this as having the potential to exacerbate the problem of adverse selection that already plagues insurance markets. Insurance industry insiders have told us that they pool and aggregate the data so that these effects wash out.

Even prior to the COVID-19 pandemic, InsurTech was believed to be the biggest FinTech vertical to watch going forward. According to Venture Scanner data, InsurTech start-ups raised almost $\$ 6.7$ billion in funding in 2019 which was up from $\$ 3.87$ billion the year before and $\$ 3.7$ billion in 2017. It seems that the pandemic has provided even more lift to this already promising area. Given the growing use of telemedicine (which often integrate payments and insurance claims through none other than InsurTech solutions), the health and medical insurance corner of the InsurTech vertical is likely to see increased user metrics, revenue, and provide plenty of ammunition for capital raises and strong exits when the economy recovers. With many under "stay-at-home" orders around the world, there is also less of a need for automobile insurance.

Some InsurTech companies, such as Metromile, provide pay-per-mile automobile insurance. The stay-at-home orders and local quarantines could make these products more appealing to the mainstream in the near term. Once adopted, it is possible that the superior customer experience provided by these InsurTech companies makes it easier to retain converts from traditional carriers. We can make a similar argument that we made for health and medical insurance; increased demand for these new and innovative automobile InsurTech companies will result in favorable numbers being reported by the $\mathrm{P} \& \mathrm{C}$ corner of the InsurTech vertical, likely paving the way for more investment opportunities and successful exits upon economic recovery.

\section{PropTech}

The last vertical in the FinTech Ecosystem is PropTech, short for Property Technology, which is the application of technological innovations to various activities in the real estate sectors. PropTech allows individuals and companies to make acquisition and disposal decisions and to manage a portfolio of real estate properties. It includes the ability of buyers to virtually visit properties, provides data about properties, and allows for crowdfunding of real estate projects.

\section{FinTech horizontals}

Moving down to the different emerging technologies and where they are likely to be employed, we come to the different "FinTech horizontals." The first four categories in 
FinTech horizontals are what we consider "functional areas" that are seeing the biggest changes from digital transformation and the FinTech Revolution. These are financial regulation, risk management, funding, and valuation.

The first functional area that is becoming increasingly shaken up by FinTech innovation is financial regulation. There are two ways in which FinTech innovation is affecting financial regulation and regulators. The first is how (or if) FinTech companies should be regulated. If so, then what about the Big Tech companies that are increasingly becoming involved in financial technologies? Despite large US financial institutions' lamenting about the stringent regulations imposed on financial services firms, regulatory requirements provide a barrier to entry into their respective markets. However, with the emergence of bank-like products and services being provided by both incumbent and start-up technology firms, the FinTech Revolution has provided a means for non-banks (or non-insurance companies or non-asset managers) to move into this market without being subjected to onerous regulatory requirements. In response, however, the major regulatory agencies in the USA and abroad have been working on initiatives that seek to balance stability and innovation.

Another way in which technological innovation is affecting financial regulation is with the advent of new technology that is supposed to make their tasks easier. Technological innovation in financial regulation is often referred to as RegTech (for regulatory technology) or SupTech (for supervisory technology). Much of SupTech leverages data analytics and automation to make the routine tasks of compliance in an increasingly data-driven financial world "smarter" and more efficient. Data analytics and automation are two of the "emerging technologies" that are highlighted in our FinTech Ecosystem in Fig. 1.

The remaining FinTech horizontals refer to emerging technologies. The first is Distributed Ledger Technology and Blockchain. While Blockchain is often associated with cryptocurrencies, the technology has much farther-reaching applications to financial services. These applications include settlement and clearing in over-the-counter derivative markets, Smart Contracts, parametric insurance, trade finance, and real estate transactions. The next emerging technology is the Internet-of-Things (IoT) which refers to connected devices. These include devices such as smart watches, fitness trackers, electronic home assistants (e.g., Amazon Alexa, Google Home), smart thermostats (e.g., Nest), and many others still in the proof-of-concept phase. There are many other ways in which connected devices and IoT technology can be tied into financial services applications. For example, having a smart thermostat linked to an energy supplier's billing system can arrange for real-time payments, assist with demand-based pricing, and even help users manage their usage to keep costs down.
Artificial intelligence (AI) is becoming a very real part of financial services, as we move to the next emerging technology in the FinTech Ecosystem. Much of the digital transformation that we are seeing in financial services can be attributed to automation and the integration of AI. According to a 2019 Barron's survey, 60\% of financial industry executives indicated that they intend to utilize AI in conjunction with Big Data Analytics, the next emerging technology in the FinTech Ecosystem, to improve business intelligence and garner deeper insights. ${ }^{5}$

Although AI becomes increasingly more prevalent across the FinTech Ecosystem's verticals - and even more broadly across financial services-there will continue to be demand for humans to manage the process. There is no indication that the "technological singularity" discussed in science fiction and pop culture is upon us. Despite being able to perform complex tasks, machines and decision support software are heavily dependent on data and code. Thus, it is not that machines and AI are "replacing" the workforce on trading floors and in banks, but rather they represent part of a broader shift of skillsets needed in the industry as a result of digital transformation.

The next emerging technology is Big Data Analytics which goes hand-in-hand with AI applications in financial services. Much of the growth of FinTech from 2009 to 2019 comes from harnessing the power of Big Data Analytics on unstructured and/or non-standard data to obtain more valuable insights into things such as lending decisions, customer acquisitions, and investment opportunities across virtually all of the FinTech verticals. Technical details on the methodologies go well beyond the scope of this article. A new area of examination is the use of "alternative data" by financial services providers including social media posts, earnings call transcripts, data collected from sensors and wearable devices, and even satellite imagery.

Consider the following example. Suppose an equity analyst is bullish about a hardware retail chain whose stock price has been steadily increasing for the past four months. This is what traditional technical analysis would refer to as a "momentum signal." Suppose that in the next few weeks the hardware retail chain will be releasing its annual earnings report and it is expected to beat consensus earnings. Typically, analysts' expectations are on the basis of multiples and/or valuations derived from pro-forma financial statements (i.e., fundamental analysis). However, this analyst wants to make an even more compelling case to a client about his or her bullish view on the stock. One thing that the analyst can do is to utilize unstructured, non-standard data, and machine learning methodologies, for example satellite imagery of hardware retail stores' parking lots. The analyst

\footnotetext{
$\overline{5 \text { See Likens }}$ (2019)
} 
then can compare images of the parking lot from last year to images of the same parking lot from this year to assess if there have been more customers visiting the store. This does not mean that sales are up, but it would present a potentially valuable signal. The problem is that this task-scouring hundreds of satellite images-is time-consuming and would be prone to human error. For example, what if there is a speck of dust on the equity analysts screen and then mistaken for a cluster of cars thereby overestimating the number of customers? This is where machine learning shows some of its promise as it turns out to be a classification problem with unstructured data (image recognition) and a standard algorithm such as a neural network can be trained to identify cars versus other [non-car] objects. This is then translated into numerical form so that the data can be quantified and compared. ${ }^{6}$

As more and more financial activities are performed digitally via computer, mobile devices, and even wearables, cybersecurity will continue to be a critical issue. This is the next major horizontal because it is imperative for any financial or technology company to invest in cybersecurity if they collect and store personal data. News about major data breaches of financial and personal data from banks and other intermediaries are becoming more common. While the convenience of FinTech services is certainly appealing-especially for certain demographics, as we discuss below-this convenience must be evaluated in the face of potential security concerns. Fear of identity theft and that one's data are not secure is a reason why a customer may be reluctant to adopt a FinTech solution as a replacement for a traditional service. Therefore, to tap into new markets, FinTech companies need to be able to convince prospective customers that their data are handled with the utmost care. Furthermore, when a firm's cybersecurity breach is made public, the fallout is likely to setback the firm's growth at least in the short term but perhaps even permanently.

Biometrics, which refers to the use of physical characteristics for digital identification, is the next emerging technology in our FinTech Ecosystem. Biometrics is not a new technology, per se, but the capabilities are expanding very rapidly and the applications to financial services are growing as well. Because certain physical markers are unique to every individual-fingerprints, the arrangement of blood vessels in the retina, or the geometric makeup of facial structure, for example-a natural application of facial recognition goes hand-in-hand with the previous emerging technology we discussed: cybersecurity. Rather than carrying around or memorizing dozens of different passwords and PINs for different accounts, the use of a fingerprint or a facial scan can be used for authentication and access. Beyond cybersecurity,

$\overline{6}$ This is described in more detail in Simonian et al. (2018). the customer experience has the potential to be changed as a result of increasing reliance on biometrics. Emerging technologies that allow one to pay with your face (via facial recognition software) or authorize a withdrawal from your bank account with a thumbprint, will make performing these tasks even easier and more convenient.

Open-source computing and the use of application programming interfaces (API's) are becoming integral to the success of FinTech companies. In fact, the European Union is pushing the largest banks to work with, rather than against, FinTech companies by providing secure access to their data. This is due in large part to the global trend to use open-source technology and API's to enable third-party developers to build applications and services that tie into the financial institutions' systems and product offerings. However, privacy concerns are making it difficult for firms in the USA to embrace open banking and data-sharing protocols. The consequence of this is that FinTech innovations in this space are being slowed down in the USA relative to Europe. Again, this comes back to the delicate balance of security/ privacy and convenience/FinTech advancement.

Cloud computing, the next emerging technology, has the potential to replace the messy legacy mainframe systems on which financial institutions still rely. Cloud computing refers to the migration of enterprise-wide storage to the internet rather than utilizing on-site or data-center server-based storage. The upside for cloud computing for financial services is high: by not having the data stored in one physical location, there is built-in redundancy which provides contingencies in the event of an operational mishap. Additionally, the entire organization can access the same data, in the same format, anytime from anywhere in the world (with an internet connection). This is an area where some of the biggest technology leaders are wrestling for market share and, as some of the largest financial institutions in the world forge partnerships with these companies' cloud computing platforms, the dividing line between Big Tech and Big Banks will become further blurred. This is one of the emerging risks. Add to that the fact that in 2018 Amazon controlled almost 50\% of the public cloud market, ${ }^{7}$ there is a potential systemic risk brewing in this space. It is no wonder the Financial Stability Board in its 2017 white paper entitled "Financial Stability Implications from FinTech" noted that third-party data management and cloud computing vendors represent one of the "priority areas" on which global regulators should keep watch. ${ }^{8}$

Another emerging technology on the computing side that has many exciting implications for financial services

\footnotetext{
7 https://www.gartner.com/en/newsroom/press-releases/2019-0729-gartner-says-worldwide-iaas-public-cloud-services-market-grew31point3-percent-in-2018.

${ }^{8}$ See Financial Stability Board (2017).
} 


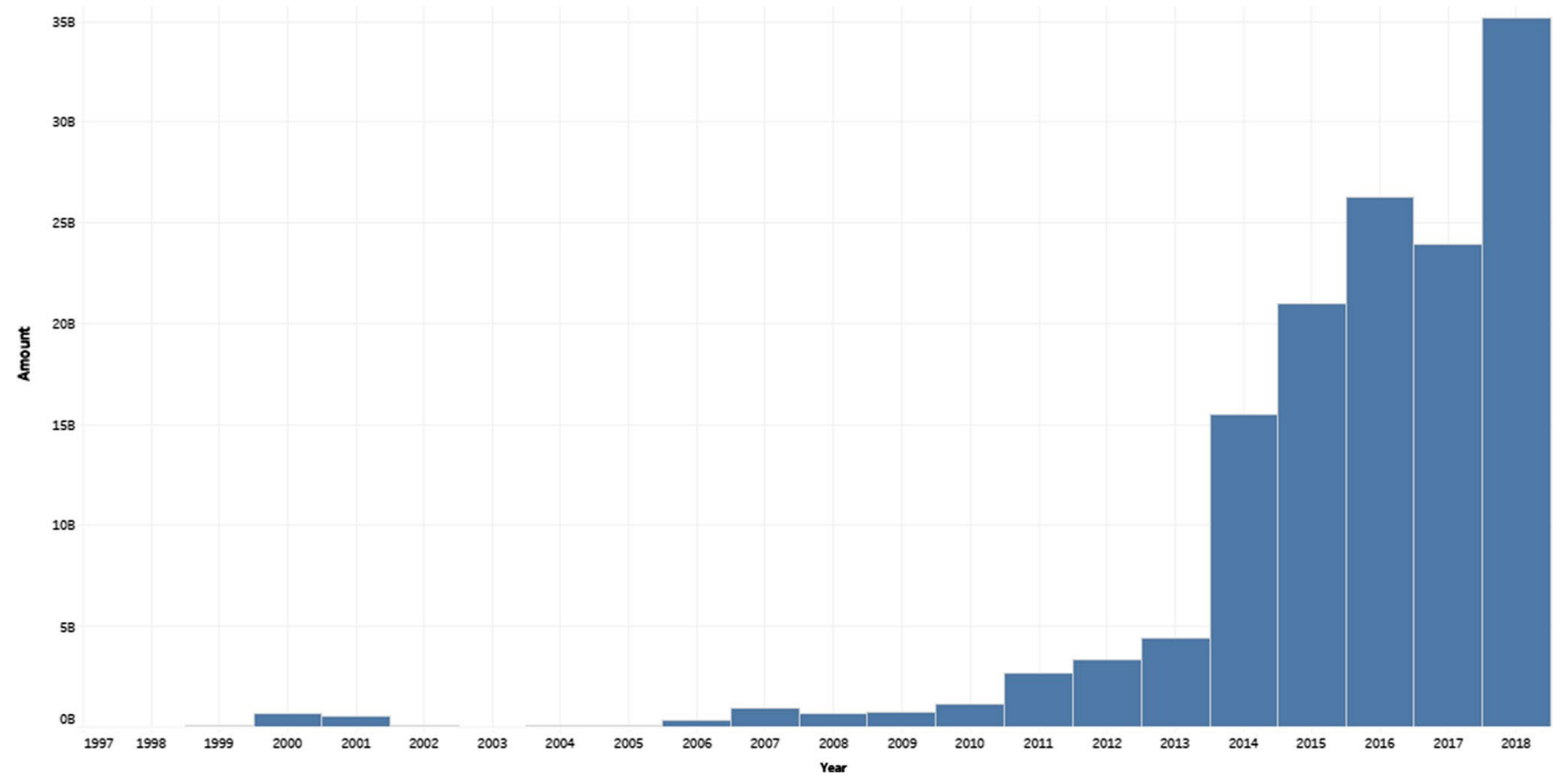

Fig. 3 Total FinTech funding amounts per year from 1997 to 2018 (sum of rounds occurring within a calendar year). Source: Prepared by the authors using Venture Scanner data

leverages the theoretical understanding of quantum mechanics to develop processors that can perform calculations orders of magnitude faster than traditional computers.

For investors looking to make more broad plays in emerging technologies with applications to transforming financial services-rather than focusing on the individual sectors or FinTech horizontals - they can consider investing in funds that specialize in the technologies that are of particular interest. For example, suppose an investor is bullish on the promise of quantum computing. One simple strategy would be to invest in publicly traded companies that have committed resources to developing and commercializing quantum computing solutions, such as IBM or Google's parent company Alphabet. And even broader approach would be to identify and invest in an ETF that tracks indexes on quantum computing companies.

\section{The FinTech Revolution}

FinTech funding amounts really took off after 2010 as shown in Fig. 3.

While it is difficult to pinpoint what exactly was the catalyst for so much investment in FinTech innovation, it is clear from a macroeconomic perspective what happened around that time. From 2007 to 2009, the world was plunged into the worst financial crisis it has seen since the Great Depression (1929-1930). In the aftermath of the GFC, there was a loss of confidence in the major financial institutions to whom people entrusted their money: big banks, insurance companies, brokers, lenders, and asset managers. It was at this critical juncture that technology firms found themselves with a unique opportunity. It just so happened that the GFC coincided at a time when the "Fourth Industrial Revolution" was getting underway. The Fourth Industrial Revolution-a term coined by Klaus Schwab of the World Economic Forumrefers to the "profound and systemic" change whereby new technological innovations blur the lines between disciplines and across physical and digital domains simultaneously. ${ }^{9}$

According to Schwab, unlike the First Industrial Revolution which was defined by the steam engine, railroads, and other mechanical innovations, the Second Industrial Revolution which was brought about by widespread use of electricity and assembly lines in manufacturing, or the Third Industrial Revolution which plunged society into the computer age with the advent of personal computers and the internet, the Fourth Industrial Revolution is being brought about by a confluence of new technologies that span biology, engineering, commerce, and transportation. As a result, every industry is becoming digitized and is undergoing rapid transformation. In fact, in order to understand how the rise of new technologies, which coincided with the end of a painful GFC, we need to define a concept known as digital transformation.

\footnotetext{
$\overline{9}$ See Schwab (2017).
} 


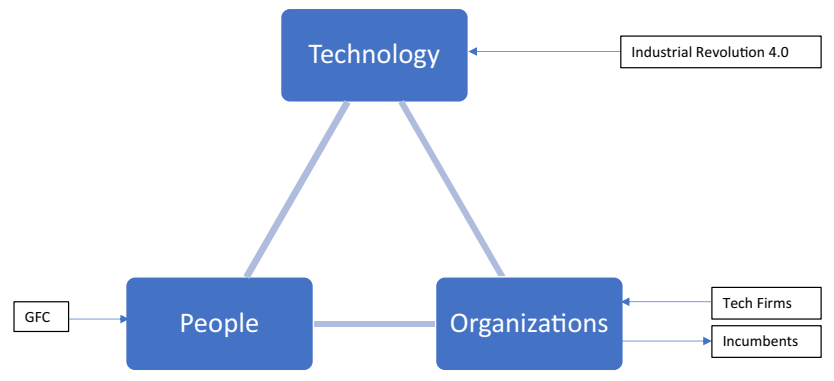

Fig. 4 The digital transformation triangle and FinTech. Source: Prepared by the authors

Digital transformation, as defined by George Westerman, refers to "the use of technology to radically improve performance" of an organization and intimately relies on the intersection of technology, people, and processes. ${ }^{10}$ Westerman points out that technology changes faster than people and organizations which is what makes a successful digital transformation challenging. ${ }^{11}$ In order for a digital transformation to take hold, there must be readiness on the part of the people-especially consumers and employees-as well as the organizations themselves. These three elementstechnology, people, and organizations - are represented by the "Digital Transformation Triangle" shown in Fig. 3.

The dynamics of this relationship, as it pertains to the FinTech Revolution, is also shown in Fig. 3. For digital transformation to take effect, there must be champions or catalysts at each one of the three elements. With respect to FinTech, there was the following. First, technological advancement benefited from the growth of FinTech coinciding with the Fourth Industrial Revolution. Then, from the "people" angle, the willingness and even eagerness of customers to consider alternative providers of financial services beyond traditional financial institutions was prompted by a lack of trust and confidence in those institutions in the wake of the GFC. With respect to organizations, there were two forces at play: Technology firms - including many start-ups—had the wherewithal to step into this role, seizing the opportunity to fill the void and gain consumers' confidence, while incumbent financial institutions were reluctant to embrace (and/or were ignorant) about the potential of these new technologies. Therefore, these represent the technology, people, and organizations, respectively, that played the necessary roles in the digital transformation in financial services. In fact, it was the incumbents not being ready to engage in this "radical improvement" via technology that paved the way for new entrants to emerge. Hence, the FinTech Revolution "rose from the ashes" of the GFC.

As the Fourth Industrial Revolution was getting underway - with smart phones, wearable devices, and applied AI becoming more user-friendly and commonplace-the technology was ripe for digital disruption. This is the top vertex in Fig. 4. Moreover, with the GFC in everybody's recent memory, the "people" part of the digital transformation was there from the customer's perspective as shown by the lower left vertex of Fig. 4. With almost a quarter of a quadrillion dollars of global wealth at stake, the question was to whom the masses are going to entrust their asset management, banking, investments, insurance, and transactional needs when the largest names in financial services had their reputations tarnished by the GFC.

This takes us to the organizational element in the lower right vertex in Fig. 4. That is where technology firms, many of which were mere start-ups, entered the fray. With new user-friendly interfaces and a customer-first philosophy, these non-banks were able to move into the markets for all the financial services mentioned earlier. So, the customersthe ones who have the wealth-were ready for an alternative to traditional financial services. From an organizational perspective, technology start-ups being naturally more agile were able to make the move, whereas the incumbents were not. Most traditional financial institutions, with the exception of a few such as Capital One Financial, shied away from the technological innovations and many of the emerging technologies discussed earlier, dismissing them as merely fads. So as the incumbents stood idle, following the same business models that they adopted for the past century. Enter the tech firms: first start-ups backed by venture capital groups ${ }^{12}$ and then the Big Tech firms (Google, Amazon, Facebook, Apple, Microsoft, Alibaba, and Tencent), all of whom by 2019 had laid some stake in the FinTech market. As the incumbents removed themselves from the transformation that was going on and minimizing the importance of the challengers to their business model - tech start-ups and Big Tech alike-the FinTech Revolution was underway. The process of existing market leaders and incumbents being inert in the face of innovation and change and potentially being displaced by new market entrants is part of a process formally referred to in the innovation literature as "disruption," a term coined in the mid-1990s by Clayton Christensen. ${ }^{13}$ And disruption is what we have seen in FinTech over the past decade.

\footnotetext{
$\overline{10}$ See Westerman et al. (2014) and Westerman (2016).

11 See Westerman (2019).
}

\footnotetext{
12 Venture capitalists represent an important player in the "Funding" functional area/horizontal of the FinTech Ecosystem.

13 See Christensen (1997).
} 


\section{Conclusion}

In this article, we developed a conceptual framework for understanding how technology is transforming financial services or FinTech. Our framework is predicated upon two conceptual underpinnings, both of which can be used by investors who are looking for value in the growth of FinTech in the future. The first is our FinTech Ecosystem which views technological innovations across different sectors within finance- the FinTech verticals-as well as the different functional areas and emerging technologies that tend to span all areas-the FinTech horizontals. We discussed how FinTech verticals can be used to perform a kind of sector analysis when seeking FinTech exposure as an alternative investment. Over the course of this discussion, we provided examples of fund flows from venture capitalists and other investors into start-ups across each of the FinTech verticals. We also provided some insight as to where we feel the next opportunities are going to be, with InsurTech topping the list. We then discussed some of the exciting emerging technologies that are being applied to financial services and how investors might achieve more broad-based exposure to those technologies.

The second conceptual underpinning supporting our framework is what we call the Digital Transformation Triangle. We explained how FinTech essentially "rose from the ashes" of the GFC in 2008-2009. That same framework can be used to predict which areas of FinTech innovation are going to thrive coming out of the COVID-19 pandemic and which may fall by the wayside. Using the Digital Transformation Triangle, the "People" vertex has clearly been impacted by the catalyst of stay-at-home measures and social distancing. What this has done is force people to bank, invest, and pay their bills remotely rather than face-to-face with human representatives. The "Organization" vertex is being impacted by the perpetual game of tug-of-war that is being played between financial incumbents that are trying the best they can to bring their digital offering up to speed to accommodate the increased demand for online and mobile products and FinTech start-ups that have the digital products with superior user experience but lack the brand recognition. At the "Technology" vertex, we are likely to see more of the emerging technologies highlighted in our FinTech Ecosystem moving more into the mainstream. Another trend at the "Technology" vertex is the more seamless integration of financial services with e-commerce apps (curbside pickup and contactless delivery) and healthcare. It will be interesting to see how this plays out, but there will be no shortage of opportunities for forward-thinking investors who are looking to capitalize on innovation and help bring the next generation of technologies to the market.

\section{References}

Christensen, Clayton M. 1997. The Innovator's Dilemma. Boston, MA: Harvard Business School Press.

Financial Stability Board. 2017. "Financial Stability Implications from FinTech: Supervisory and Regulatory Issues that Merit Authorities' Attention". https://www.fsb.org/wp-content/uploads/R2706 17.pdf. Retrieved 24 June 2017.

Likens, Scott. 2019. How Artificial Intelligence Is Already Disrupting Financial Services. Barron's Online. Retrieved May 16, 2019, from: https://www.barrons.com/articles/how-artificial-intelligen ce-is-already-disrupting-financial-services-51558008001.

Schwab, Klaus. 2017. The Fourth Industrial Revolution. New York, NY: Penguin Random House.

Simonian, Joseph, Marcos López de Prado, and Frank J. Fabozzi. 2018. Order from Chaos: How Data Science Is Revolutionizing Investment Practice. The Journal of Portfolio Management 45(1): 1-4.

Westerman, George, Didier Bonnet, and Andrew McAfee. 2014. The Nine Elements of Digital Transformation. MIT Sloan Management Review 55(3): 1-6.

Westerman, George. 2016. Why Digital Transformation Needs A Heart. MIT Sloan Management Review 58(1): 19-21.

Westerman, George. 2019. The First Law of Digital Innovation. MIT Sloan Management Review 52(3): 326-349.

Publisher's Note Springer Nature remains neutral with regard to jurisdictional claims in published maps and institutional affiliations.

Michael B. Imerman is an Assistant Professor of Finance at the Drucker School of Management in Claremont Graduate University where he is also Co-Director of the Financial Engineering Program. He was previously on the Finance faculty at Lehigh University from 2012 to 2018. Prior to that appointment Dr. Imerman was a Postdoctoral Research Associate at Princeton University in the Department of Operations Research and Financial Engineering where he worked on high-frequency econometrics, volatility modeling, and financial data science. He holds a Ph.D. in Finance and Economics from Rutgers University, and a B.S. in Finance from Rutgers Business School in 2004. He has worked in industry as a Finance Analyst at Lehman Brothers in Equity Derivatives and Fixed Income/Credit Trading. Imerman's areas expertise include FinTech innovation, banking, credit risk, and risk management. Since 2018 he has been on the Editorial Advisory Board of the Journal of Financial Data Science.

Frank J. Fabozzi is a Professor of Finance at EDHEC Business School and a Senior Scientific Adviser at EDHEC-Risk Institute. He is a trustee of the BlackRock fixed-income fund complex. He is the editor of The Journal of Portfolio Management and cofounder and co-editor of The Journal of Financial Data Science. He is the CFA Institute's 2007 recipient of the C. Stewart Sheppard Award and the CFA Institute's 2015 recipient of the James R. Vertin Award. He was inducted into the Fixed Income Analysts Society Hall of Fame in November 2002. Fabozzi received his BA and MA in economics in 1970 from The City College of New York where he was elected to Phi Beta Kappa and a $\mathrm{PhD}$ in economics in 1972 from the City University of New York. He has earned the designations of CFA and CPA. 